\title{
Effects of remediation reagents and rainfall on self-potential signals: A case study
}

\author{
Yung-Chieh Chuang ${ }^{1}$, Chien-Chih Chen ${ }^{1, *}$, Tzu-Pin Wang ${ }^{1,2,3}$, Tien-Hsing Tung ${ }^{4}$, Yao-Tsung Chen ${ }^{4}$, \\ Su-Tien Lin ${ }^{5}$, and Ching-Jen $\mathrm{Ho}^{6}$ \\ ${ }^{1}$ Department of Earth Sciences and Graduate Institute of Geophysics, National Central University, Taoyuan City, Taiwan \\ ${ }^{2}$ Disaster Reduction Research Center, Chien Hsin University of Science and Technology, Taoyuan City, Taiwan \\ ${ }^{3}$ Geophysical Technology and Engineering Co., Ltd., Taipei City, Taiwan \\ ${ }^{4}$ Apollo Technology Co., Ltd., Taipei City, Taiwan \\ ${ }^{5}$ Forever Geotech Consultants Co., Ltd., Taipei City, Taiwan \\ ${ }^{6}$ Environmental Protection Administration, Taipei City, Taiwan
}

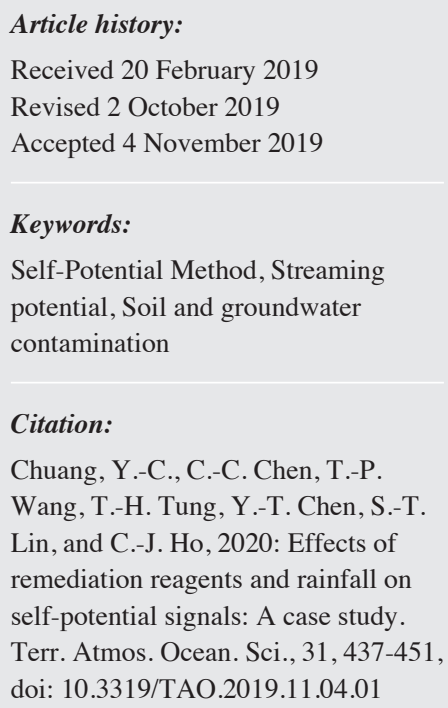

Received 20 February 2019

Revised 2 October 2019

Accepted 4 November 2019

Keywords:

Self-Potential Method, Streaming potential, Soil and groundwater contamination

Citation:

Chuang, Y.-C., C.-C. Chen, T.-P Wang, T.-H. Tung, Y.-T. Chen, S.-T. Lin, and C.-J. Ho, 2020: Effects of remediation reagents and rainfall on self-potential signals: A case study. Terr. Atmos. Ocean. Sci., 31, 437-451, doi: 10.3319/TAO.2019.11.04.01

\begin{abstract}
In this study, the self-potential (SP) method was used for the continuous monitoring of naturally occurring electric potential differences at a soil and groundwater contamination site in Southern Taiwan from August to October 2015. At this field site, we set two perpendicular survey lines with 25 potential electrodes for daily measurements. The hourly SP medians of each day were averaged for the inversion of the 85-m long north-south (line I) and 35-m-long west-east (line II) SP tomographies (SPTs). The results are as follows: First, the regional groundwater flow direction was found to be in the north-northeast direction according to the distribution of electric potentials in the SPTs. The rainfall effects and consequent SP response were analyzed, which revealed enhanced regional positive and negative potentials in the SPTs, with a strength of up to $-100 \mathrm{mV}$. In addition, effects of remediation reagent injection were monitored from 13 to 18 October; the results showed increased local potential in the two SPTs. Finally, we assessed the movement of the isopotential lines within a specific distance and determined the apparent velocity of groundwater to be $3.24 \pm 0.38$ and $0.57 \pm 0.08 \mathrm{~m}$ day $^{-1}$ through the dissipation of rainfall effects and local potential increases because of the injection.
\end{abstract}

\section{INTRODUCTION}

Geotechnical investigations conducted at a soil and groundwater contamination site include drilling, sampling, and chemical analysis. However, the subsequent designing and planning of environmental remediation engenders problems because of high operating costs and time-consuming protocols. Therefore, completely examining a contaminated area and evaluating the contamination spread rate are difficult.

In recent years, geophysical exploration technology has been gradually applied in the investigation and monitoring of soil and groundwater contamination because of its low cost, high monitoring efficiency, and complete scope of

\footnotetext{
* Corresponding author

E-mail: chienchih.chen@g.ncu.edu.tw
}

contamination distribution (Atekwana and Atekwana 2010). This technology includes the ground-penetrating radar technique (Benson et al. 1997; Sauck et al. 1998; Annan 2005), electrical resistivity tomography (Binley and Kemna 2005; Wang et al. 2015), electromagnetic induction (Everett and Meju 2005), induced polarization (Slater and Lesmes 2002; Sogade et al. 2006), and the self-potential (SP) method (Revil et al. 2006), which can detect the physical characteristics of several substances tens of meters deep.

The SP method adopted in this study has been widely applied in geophysical exploration. In particular, novel breakthroughs have been made through its application in hydrogeological areas in the past two decades. These applications include slope stability research (Mauritsch et al. 2000; Lapenna et al. 2003; Colangelo et al. 2006), dam collapse mechanism analysis (Al-Saigh et al. 1994; Trique et al. 
1999; Sheffer and Howie 2001, 2003; Bolève et al. 2011), geothermal fluid movements in volcanic sites (Tanaka 1993; Hashimoto and Tanaka 1995; Patella 1997), and groundwater level variation (Fournier 1989; Birch 1993) and contamination analyses (Baker and Cull 2004; Naudet et al. 2004; Arora et al. 2007; Martínez-Pagán et al. 2010).

In this study, the SP in a soil and groundwater contamination site in Southern Taiwan was continuously monitored to analyze rainfall effects and the response of a reagent injection. We analyzed the rainfall effects in SP signals by eliminating the electric potential trend as previous published methods from Naudet et al. (2003) and Jardani et al. (2009). Besides, with the inversion program SP2DINV developed by Soueid Ahmed et al. (2013), we obtained the daily SP tomographies (SPTs) and observed the enhanced regional electric potentials during the reagent injection. In the last, we evaluated the apparent velocity of groundwater through the dissipation of rainfall effects and local potential increases.

\section{METHODOLOGY}

\subsection{Principles of the Self-Potential Method}

The SP method is a type of passive geophysical technology for geoelectrical exploration. It investigates the presence of groundwater, natural gas, petroleum, and mineral deposits by measuring variations in the SP field. The field has two sources: geomagnetic disturbance and the electrical field response to the local electrochemical reactions. The field response comprises the streaming (electrokinetic), mineral, thermoelectric, and membrane (diffusion) potentials (Corwin and Hoover 1979). In the absence of the mineral potential (several hundreds millivolt), SP is typically considered the streaming potential (less than $100 \mathrm{mV}$ ) because the SP generated by the thermoelectric and membrane potentials is comparatively low (less than $10 \mathrm{mV}$ ) (Perrier et al. 1999; Jouniaux et al. 2000; Milsom 2007; Atekwana and Atekwana 2010).

The streaming potential arises from the difference in the fluid pressure, as follows (Bolève et al. 2009):

$\Delta \mathrm{V}=\mathrm{C} \Delta \mathrm{P}$

where $\mathrm{V}$ is the streaming potential $(\mathrm{V}), \mathrm{P}$ is the groundwater pressure $(\mathrm{Pa})$, and $\mathrm{C}$ is the coupling coefficient $(\mathrm{V} / \mathrm{Pa})$. The streaming potential exists on the prerequisite that fluids must be present in the region to form the solid-fluid interface, generating the electrical double layer.

The electrical double layer is a structure observed at the microscopic scale, and it is an electrical charge distribution on the ore-fluid interface (solid-fluid interface). Ore surfaces typically have a layer of negative electrical charges, known as the inner stern layer (ISL). To compensate for the unbalanced electrical charges in this region, the nega- tive electrical charges on the mineral surface attract positive electrical charges from the pore water. The ISL and first layer of positive electrical charges on the outer side (the outer stern layer, OSL) are collectively called stern layers (SLs). SLs are electrical formations on the solid surface with the highest Coulomb force and cannot be easily separated by external shear forces.

Further outside the OSL is the diffuse layer, which is considered the solid-fluid interface. The first layer in the diffuse has very high Coulomb force; however, the positive electrical charges typically outnumber the negative charges. At the interface between the end of this layer and the next layer is the shear plane. It can be interpreted as a plane that can be sheared open, indicating that the electrical charges outside this plane can be disturbed and separated by external shear forces (Glover and Jackson 2010).

\subsection{Field Site and Self-Potential Configuration}

The study site was contaminated with organochlorides, such as trichloroethylene and tetrachloroethylene, and their degradation products, 1, 2-dichloroethane, cis-1, 2-dichloroethane, and vinyl chloride. The site was composed of holocene paleochannel alluvium, including gravel, sand, silty sand, and mud. In addition, it had interbedded sandstone and shale. The drilled soil samples revealed backfilled soil $3 \mathrm{~m}$ below the surface, a 4-m-thick layer of silty clay, a 7-mthick layer of fine sand, and a 6-m-thick layer of silty clay successively downward. The groundwater level had a mean depth of approximately $2 \mathrm{~m}$ with NNE flow direction. The groundwater flow rates and directions were measured from several wells with heat-pulse flowmeter. There is a heater in the center of flowmeter with surrounding temperature sensors. When the groundwater flows through the flowmeter, the temperature difference in different direction will be used to determine the flow rate and direction at different depths. The results will be shown in the section 4 below.

The SP survey lines were arranged to the north of the contaminated site. And the SP data were measured with carbon rod electrodes, which were buried with bentonite to decrease contact resistances. An 85-m-long survey line (line I) was set in north-south orientation, with an electrode interval of $5 \mathrm{~m}$ and 18 potential electrodes. A 35-m-long survey line (line II) was set in west-east orientation, with an electrode interval of $5 \mathrm{~m}$ and 8 potential electrodes. The intersection electrode of survey lines I and II was considered the common reference electrode. Therefore, 25 potential electrodes were continuously monitoring the naturally occurring electric potential differences with 24 receiving channels at a sampling rate of $25 \mathrm{~Hz}$ (Fig. 1).

\subsection{Data Processing}

The continuous raw SP data at a sampling rate of $25 \mathrm{~Hz}$ 


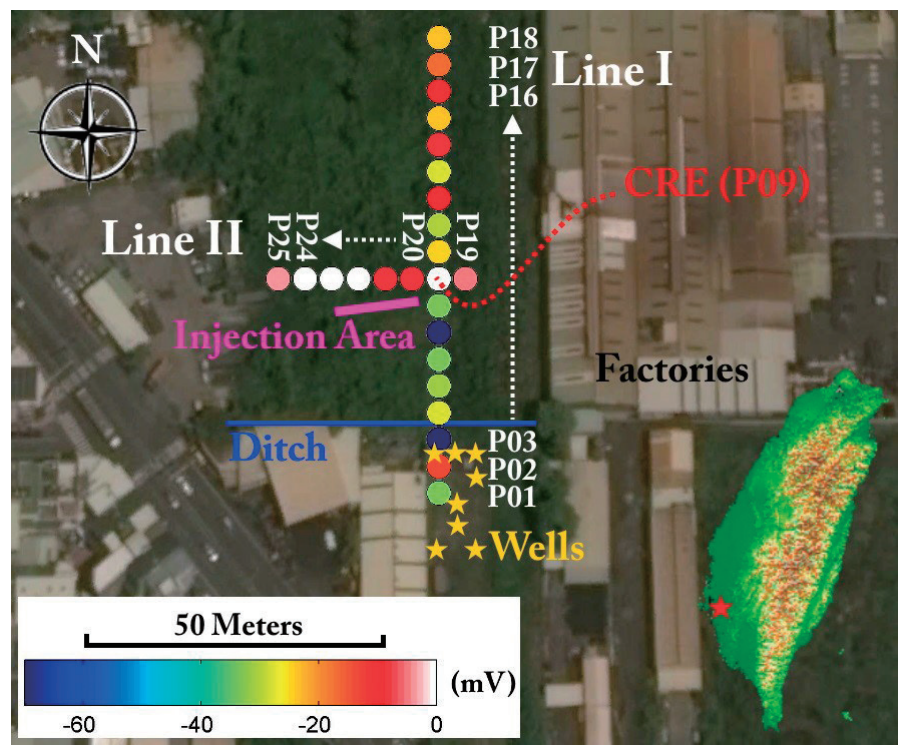

Fig. 1. Soil and groundwater contamination site in Southern Taiwan and self-potential configuration. Operational iron factories were present at both eastern and western sides of the SP survey lines; $20 \mathrm{~m}$ away from survey line I is a 50-cm-deep west-east ditch. The regional groundwater flow direction was primarily in NNE orientation. The flow rate and direction were measured with several wells, as indicated by yellow stars. The reagent injection area is located approximately at $\mathrm{x}=42 \mathrm{~m}$ of line I and at $\mathrm{x}=52-67 \mathrm{~m}$ of line II, as indicated by purple rectangles. And the injection depth is from 2 to $17 \mathrm{~m}$, with the injection periods from 13 to 18 October. CRE means the common reference electrode with potential electrode number P09. The colorbar indicates the SP values on 15 September.

are shown in Fig. 2a. SP comprises signals from natural and artificial fields. The data quality determines the stability in SPTs. Because there are many high frequency signals in the raw data, we calculate the hourly median data as marked in blue stars, and average the hourly median data to get daily average data as marked in orange stars. We could observe the quartile of the hourly median data every day is approximately $0-3 \mathrm{mV}$. It means the general data quality is stable. After data preprocessing to all receiving channels, the daily spatial SP distribution in line I is shown in Fig. 2b. Therefore, the daily spatial SP data recorded from August to October were used for SPTs inversion with the SP2DINV program (Soueid Ahmed et al. 2013) to obtain the underground distribution of electric potentials and in survey lines I and II.

The field equation to solve for the electrical problem in SP2DINV program is expressed by

$\nabla \cdot(\sigma \nabla \mathrm{V})=\nabla \cdot \mathbf{J}_{\mathrm{s}}$

where $\sigma$ is the electrical conductivity $(\mathrm{Ohm}-\mathrm{m})$, and $\mathbf{J}_{\mathrm{s}}$ is the streaming current density $\left(\mathrm{A} \mathrm{m}^{-2}\right)$. Equation (2) is solved with the following boundary conditions:

$\mathrm{V}=0$ at $\Gamma_{\mathrm{D}}$

$-\mathbf{n} \cdot\left[\sigma \nabla \mathrm{V}-\mathbf{J}_{\mathrm{s}}\right]=0$ at $\Gamma_{\mathrm{N}}$ where $\mathbf{n}$ is the unit vector normal to the boundary $\Gamma_{\mathrm{N}}$. Through the inversion of SP signals, we predicted the solution $\mathbf{J}_{\mathrm{s}}$ from the daily spatial SP data, and obtained the underground distribution of electric potentials by forward modeling (Soueid Ahmed et al. 2013).

In the inverse modeling, the objective function $\Phi_{\mathrm{T}}$ can be reformulated in the standard form

$\Phi_{\mathrm{T}}=\left\|\mathbf{G m}-\mathrm{V}^{\mathrm{obs}}\right\|_{2}^{2}+\lambda^{2}\left\|\mathbf{m}-\mathbf{m}_{0}\right\|_{2}$

where $\mathbf{G}$ is the kernel matrix corresponding to the self-potential, $\mathbf{m}$ is the current density model, and $\lambda$ is a regularization parameter under the constraint that $0<\lambda<\infty$. The value of the regularization parameter balances the data misfit term and the regularizer. In absence of a prior model $\left(\mathbf{m}_{0}=0\right)$, the solution of the problem corresponding to the minimum of the cost function C is given by Hansen (1998) as

$$
\widehat{\mathbf{m}}(\lambda)=\left[\mathrm{G}^{\mathrm{T}} \mathrm{G}+\lambda^{2} \mathrm{I}\right]^{-1}\left(\mathrm{G}^{\mathrm{T}} \mathrm{V}^{\mathrm{obs}}\right)
$$

To reduce the computation time, the SP2DINV used a singular value decomposition method, which consists of rewriting the solution under the following form:

$\widehat{\mathbf{m}}(\lambda)=\left(\frac{\sigma_{\mathrm{i}}^{2}}{\sigma_{\mathrm{i}}^{2}+\lambda^{2}}\right) \frac{\mathrm{u}_{\mathrm{i}}^{\mathrm{T}} \mathrm{V}^{\mathrm{obs}}}{\sigma_{\mathrm{i}}} \mathrm{v}_{\mathrm{i}}$ 
(a)

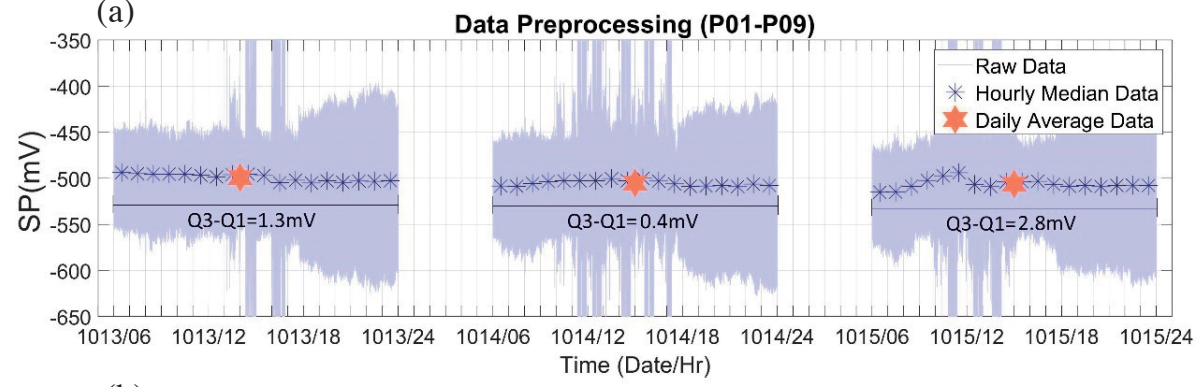

(b)

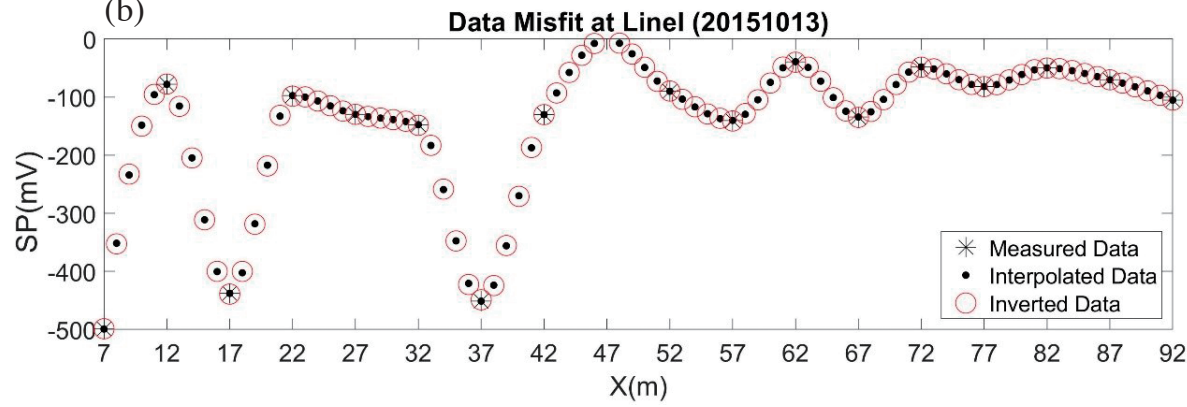

Fig. 2. Data preprocessing and spatial SP data used for SPTs inversion. (a) The blue stars are the hourly median data calculated from the raw data of potential electrodes P01 - P09, which P09 is CRE. The orange stars are the daily average data calculated from hourly median data. And the quartile of the hourly median data every day are noted below the horizontal lines. (b) The measured data are same as the daily average data in (a) with P01 at $\mathrm{x}=7 \mathrm{~m}, \mathrm{P} 02$ at $\mathrm{x}=12 \mathrm{~m}$, and so on. The Interpolated data are interpolated from the measured data with an electrode interval of $1 \mathrm{~m}$ by using cubic spline interpolation. And the inverted data are the inversion results from SP2DINV program (Soueid Ahmed et al. 2013).

$\overline{\mathbf{G}}=\sum_{\mathrm{i}=1}^{\mathrm{Q}} \mathrm{u}_{\mathrm{i}} \sigma_{\mathrm{i}} \mathrm{v}_{\mathrm{i}}^{\mathrm{T}}, \mathrm{Q}=\min (\mathrm{N}, \mathrm{M})$

where $\mathrm{u}_{\mathrm{i}}$ and $\mathrm{v}_{\mathrm{i}}$ denote the left and right singular vectors, $\sigma_{\mathrm{i}}$ are singular values which are positive and appear in decreasing order (Soueid Ahmed et al. 2013).

In the calculation, we developed a triangular mesh by using COMSOL Multiphysics (Comsol 2007, http://www. comsol.com/). The left, right, and lower boundaries were set as the Dirichlet boundary. As shown in Eq. (3), it assumed the electric potential at infinite distance was zero. And the upper boundary was set as the Neumann boundary. As shown in Eq. (4), there were no currents normal to the interface between soil and air. In the SP inverse modeling, several studies used the ERT as background resistivity, several studies used the mean value as background resistivity (Bolève et al. 2009; Martínez-Pagán et al. 2010). In this study, the electrical resistivity was set as a mean value (20 Ohm-m) to focus on the influence of remediation reagents on SP signals. The root-mean-square error was used for assessing the data fit quality, and it is defined as follows:

$\operatorname{RMSE}=\sqrt{\frac{\sum_{\mathrm{i}=1}^{\mathrm{N}}\left[\mathrm{d}_{\text {pre(i) }}-\mathrm{d}_{\text {mes }(\mathrm{i})}\right]^{2}}{\mathrm{~N}}}$

where $\mathrm{d}_{\text {pre(i) }}$ is the SP voltage calculated through inversion, $d_{\text {mes(i) }}$ is the observed SP value, and N is the total number of measurements.
Figure 3 shows the sensitivity of survey lines I and II. The sensitivity $\mathrm{S}$ in this study is defined as follows:

$\mathrm{S}_{\mathrm{x}, \mathrm{z}}=\log _{10}\left(\sqrt{\frac{\sum_{\mathrm{i}=1}^{\mathrm{N}} \mathrm{d}_{\mathrm{sl}(\mathrm{i})^{2}}}{\mathrm{~N}}}\right)$

where $\mathrm{d}_{\mathrm{sl}(\mathrm{i})}$ is the surface SP generated by the current sources of different grids in the model. A grid with a sensitivity higher than 0 indicates that the SP source in this region can produce signals higher than $1 \mathrm{mV}\left(\log _{10} 1=0\right)$ upon surface observation. Because the quartile of the hourly median data every day is approximately $0-3 \mathrm{mV}$ (Fig. 2a), the following SPTs are shown within the black frame as the reliable region (Fig. 3).

\section{RESULTS}

\subsection{Groundwater Flow Direction}

The spatial SP values on 15 September were shown in different colors as Fig. 1. The trend of the SP values in survey line I revealed that the electric potential in the north is higher than that in the south. However, the trend of the SP values in survey line II was unclear. It might imply that the primary groundwater flow direction is from south to north based on the mechanism of streaming potential. After SPTs inversion, negative and positive electric potential regions were observed to the south and north of survey line I within 

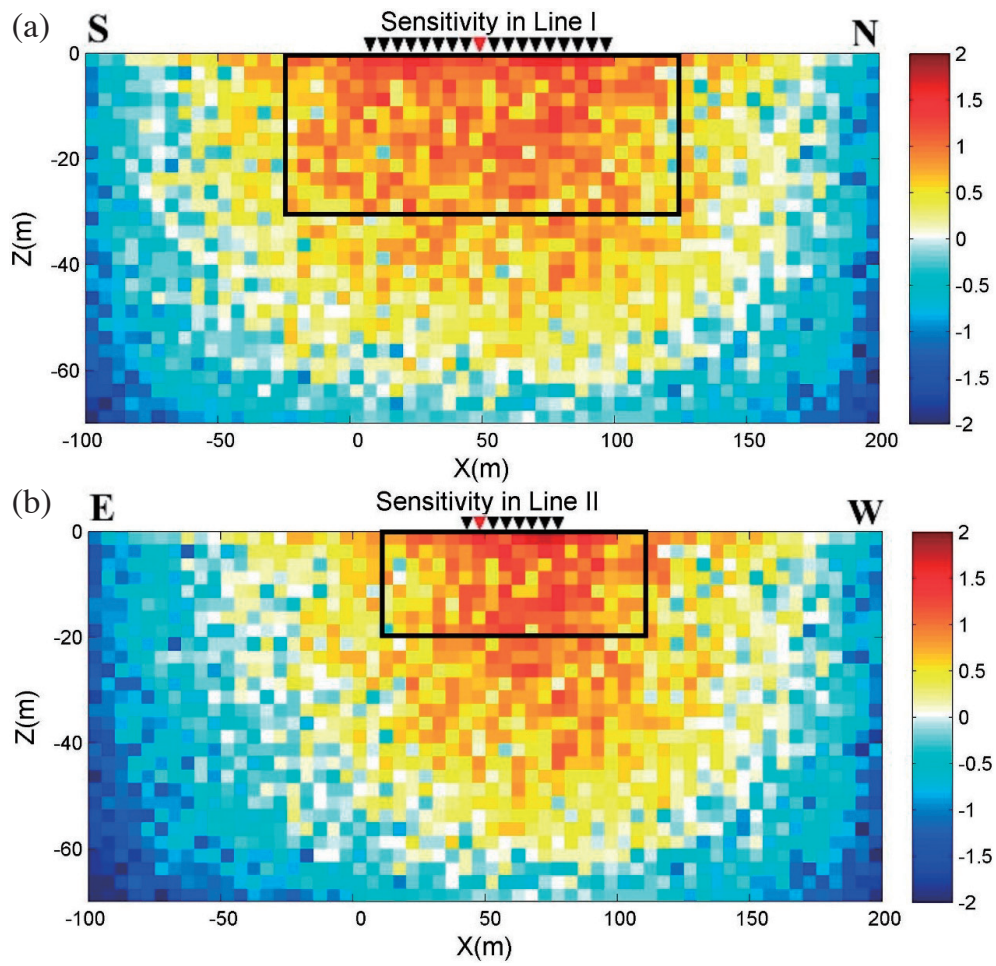

Fig. 3. Sensitivity of survey lines I and II. (a) The black arrows show the potential electrodes (P01 - P18) from $\mathrm{x}=7 \mathrm{~m}$ to $\mathrm{x}=92 \mathrm{~m}$ of survey line I; the red arrow shows the CRE P09. (b) The black arrows show the potential electrodes from $x=42 \mathrm{~m}$ to $\mathrm{x}=77 \mathrm{~m}$ (P19 - P25) of survey line II; the red arrow shows the CRE P09 at $\mathrm{x}=47 \mathrm{~m}$. The region with sensitivity $>0$ indicates that the SP source of this region can produce signals higher than $1 \mathrm{mV}\left(\log _{10} 1=0\right)$ upon surface observation. The colorbar indicates sensitivity $\mathrm{S}$ in Eq. (10).

a depth of $30 \mathrm{~m}$, and to the east and west of survey line II within a depth of $20 \mathrm{~m}$ (Fig. 4). Although there are some regional electric potential anomaly within a depth of $3 \mathrm{~m}$, even at a depth of $7 \mathrm{~m}$ at $\mathrm{x}=30 \mathrm{~m}$ of survey line I and at a depth of $7 \mathrm{~m}$ at $\mathrm{x}=65-70 \mathrm{~m}$ of survey line II, we attribute these anomalies to the backfilled soil $3 \mathrm{~m}$ below the surface. Although artificial objects may cause strong electric potential anomalies in SPTs, the background electric potential field still reveals the signals from natural.

The electric potential intensity slightly fluctuated in the SPTs from August to October 2015, it merely represented the variation in the electric potentials arising from groundwater pressure variations, as shown in Eq. (1). According to the mechanism of streaming potential, groundwater flow pulls the positive electrical charges on the outer side of the shear plane away from the inner side of the shear plane by the shear forces. Consequently, the aforementioned mechanism results in negative and positive electric potentials upstream (southern side) and downstream (northern side), respectively. This phenomenon is typically applied to determine the direction of the groundwater flow (Jardani et al. 2006; Martínez-Pagán et al. 2010). Therefore, according to the SPTs from August to October, the groundwater was inferred to flow from south to north.

For survey line II, the negative electric potential region was in the west, and the positive electric potential region was in the east, within a depth of $20 \mathrm{~m}$. According to streaming potential theory, the groundwater was inferred to flow from west to east, and it was weaker than the SPTs of survey line I (Fig.4). Considering the distribution of the electric potentials and its variations in the survey lines, the groundwater flow was inferred to be in the north-northeast direction, which is consistent with the local groundwater flow direction from well measurements as shown in the section 4 below.

\subsection{Rainfall Effects on Self-Potential}

Rainfall events considerably affect SP, and the effect can remain for as long as 1 week. Figure 5 shows the temporary bias of SP caused by rainfall events on 22 October. Although the rain started from 20th to 23rd, the water took some days to infiltrate into the aquifer, thus it showed time lag between rainfall and duration of rainfall effects in SP. As shown in Eq. (1), the streaming potential arises from the groundwater pressure. The SP variation from rainfall didn't directly result from raindrops. Indirectly, the rainfall would recharge the groundwater, and enhance the groundwater pressure. Through the mechanism of streaming potential, the SP changed. Once the groundwater was recovered to the original pressure, the SP was recovered to the background electric potential.

SP comprises the rainfall-induced and background 

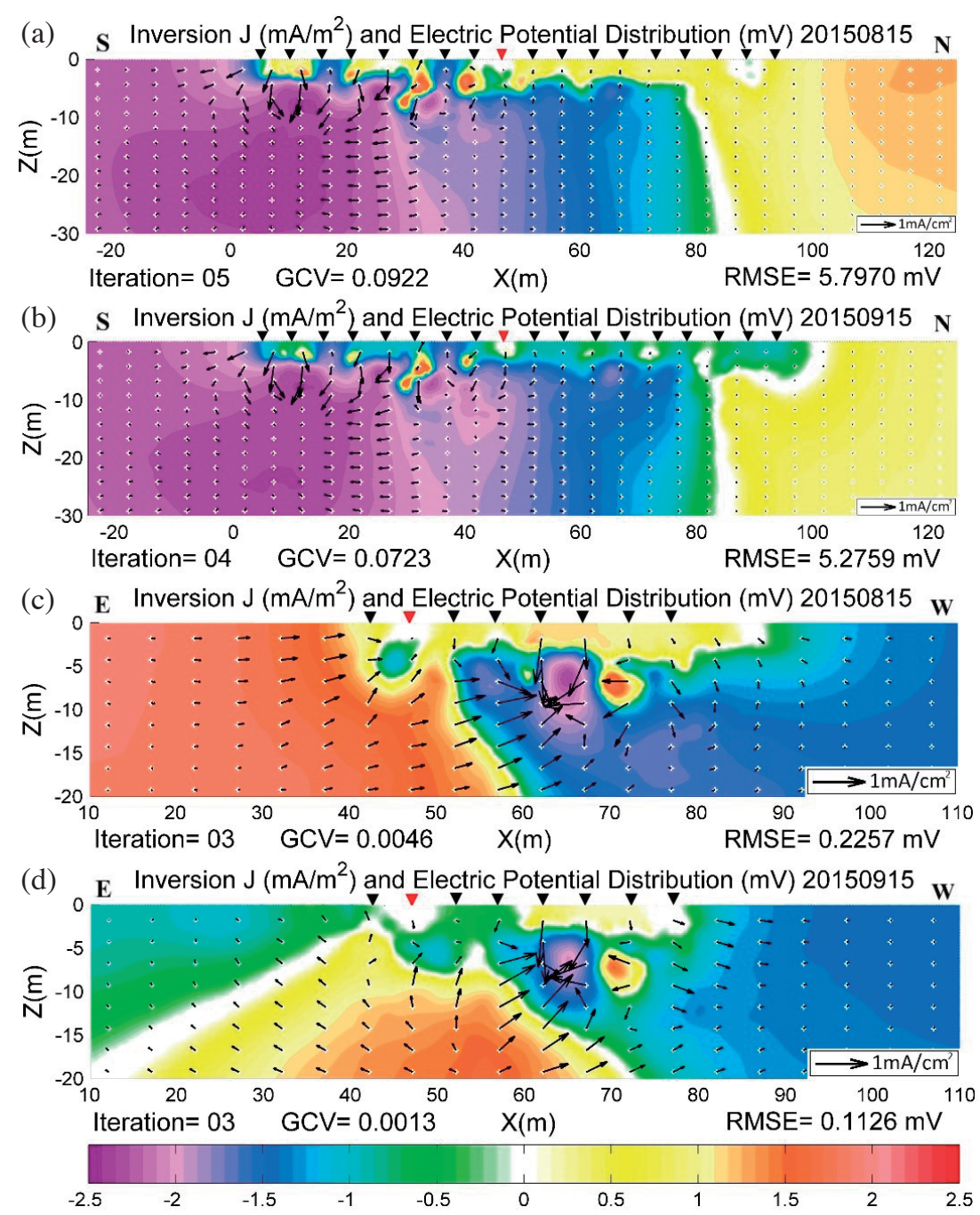

Fig. 4. Self-potential tomography of survey lines I and II on 15 August and 15 September. (a) (b) The SPTs of survey line I show negative and positive electric potentials to the south and north, respectively, hence determining the northward groundwater flow. (c) (d) The SPTs of survey line II show negative and positive electric potentials to the west and east, respectively, hence determining the eastern groundwater flow. The figure only displays the direction of current sources higher than $0.05 \mathrm{~mA} \mathrm{~m}^{-2}$; the electric potential value is indicated in a logarithmic scale, wherein the electric potential with an absolute value lower than $1 \mathrm{mV}$ is indicated as 0 . The SPT colorbar is indicated in a logarithmic scale (10 mV will show 1 in colorbar because $\log _{10} 10=1$ ). 


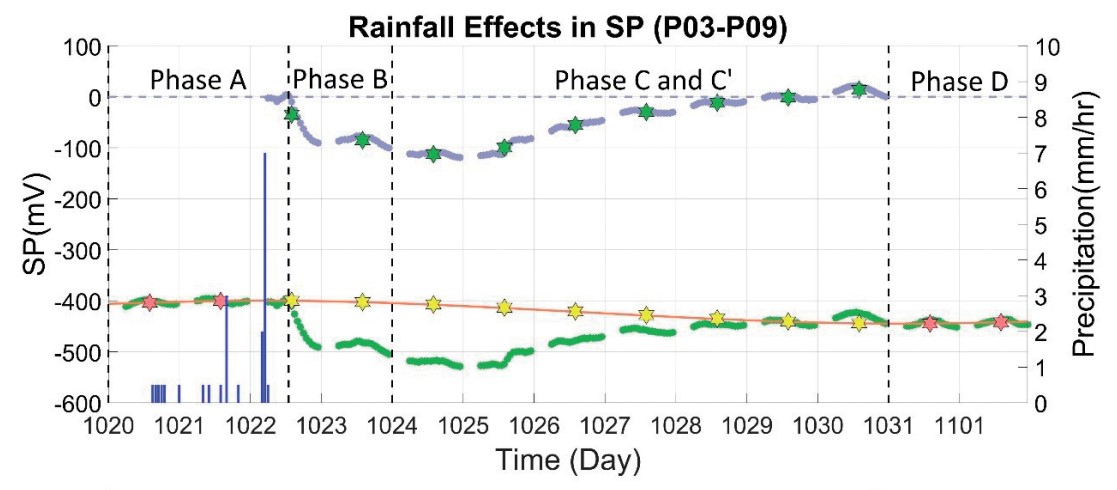

$\begin{array}{ll} & \text { Hourly Median Data } \\ \text { Fitted Data using Cubic Smoothing Spline(10/20-10/21,10/31-11/01) } \\ \text { SP Data of Rainfall Effects } \\ \text { Daily Average Data for Fitting(10/20-10/21,10/31-11/01) } \\ \text { Daily Average Fitted Data(10/22-10/30) } \\ \text { Daily Average SP Data of Rainfall Effects(10/22-10/30) } \\ \text { Precipitation }\end{array}$

Fig. 5. Observed values, theoretical values, and rainfall response values of self-potential (SP) field in P03 - P09. The observed values were the hourly median data (green dots) with same calculation process in Fig. 2a. The theoretical values not subject to rainfall effects were the fitted data (orange line) obtained by interpolating cubic smoothing spline into the SP field of Phases B and C using daily average data for fitting (orange stars). The rainfall response values of SP field (purple dots) was acquired by deducting the theoretical values from the theoretical values. The daily average fitted data (yellow stars) and daily average SP data of rainfall effects (green stars) were used as theoretical values and rainfall response values for SPTs inversion. Phase A is the background SP field period before rainfall; Phase B is the period of a sharp change in the SP field arising from rainfall; Phase C and C' is the recovery period of the SP field; Phase D is the phase for the recovery of the background SP field.

electric potential fields. Through removing the trend in hourly median data, we could derive the SP values influenced by the rainfall. Therefore, the theoretical values of SP not subject to rainfall effects was obtained by interpolating a cubic smoothing spline into the SP of 22 - 30 October. And the rainfall response values of SP was acquired by deducting the theoretical values from the theoretical values (Fig. 5), which were then used in the inversion of SPTs to show rainfall effects (Fig. 6).

The SPTs of survey line I on 22, 26, and 29 October showed that the negative electric potential at the upstream (southern side) started increasing gradually on a rainy day, and we referred to Phase B: the period of a sharp change in rainfall-induced SP (Fig. 6a). Thereafter, a positive electric potential region gradually appeared at the downstream (northern side) on 26 October. At this moment, the negative electric potential intensity had already increased to $-100 \mathrm{mV}$ at the upstream, and we referred to Phase C: the early phase for the recovery of the SP field (Fig. 6b). On 29 October, the negative and positive electric potential regions at the upstream and downstream, respectively, gradually weakened, and we called Phase C': the later phase for the recovery of the SP field (Fig. 6c). A similar rainfall-induced process can be also observed in survey line II (Figs. 6d, e, and f).

The rainfall effects on the two survey lines revealed a negative electric potential at the upstream in Phase B. The rainfall effects on Phase $\mathrm{C}$ showed gradual increases in the negative electric potential, and the positive electric potential region appeared at the downstream. Upon entry into Phase
C', both positive and negative electric potentials weakened and disappeared. Moreover, in the SPTs of survey line II, the rainfall effects on Phase $\mathrm{C}$ ended earlier on 26 October (Fig. 6f). In addition, the increase in the electric potential intensity in survey line II was weaker than that in survey line I. Regarding the rainfall-induced SP variations, we actually observed the same evolution in the SPTs of continuous rainfall and sunny days in late August and early September, respectively. This phenomenon may be related to either the infiltration process and rainfall dissipation (Revil et al. 2002) or local groundwater pressure variation (Fagerlund and Heinson 2003).

\subsection{Monitoring of Reagents Injection}

A reagent was injected nearby the crossing of the two survey lines from 13 to 18 October (Fig. 1). The reagent is composed of EcoClean- $\mathrm{E}^{\circledR}$ and EcoClean- $\mathrm{B}^{\circledR}$ from EcoCycle Corporation. It has poor fluidity so that it can stay in the stratum for an extended period. When the pollutants came in contact with the groundwater, they were blocked by the reagent, preventing pollutants' further diffusion downstream.

After eliminating the rainfall effects in observed values to get theoretical values as demonstrated in Fig. 5. The daily SPTs and SPT variations in survey line I from inversion of theoretical values are shown in Fig. 7. The daily SPTs and its variations show that a point-shaped potential increase gradually occurred at a depth of $5-17 \mathrm{~m}$ at $\mathrm{x}=40$ $\mathrm{m}$ after 13 October, and its strength was as high as $35 \mathrm{mV}$ 

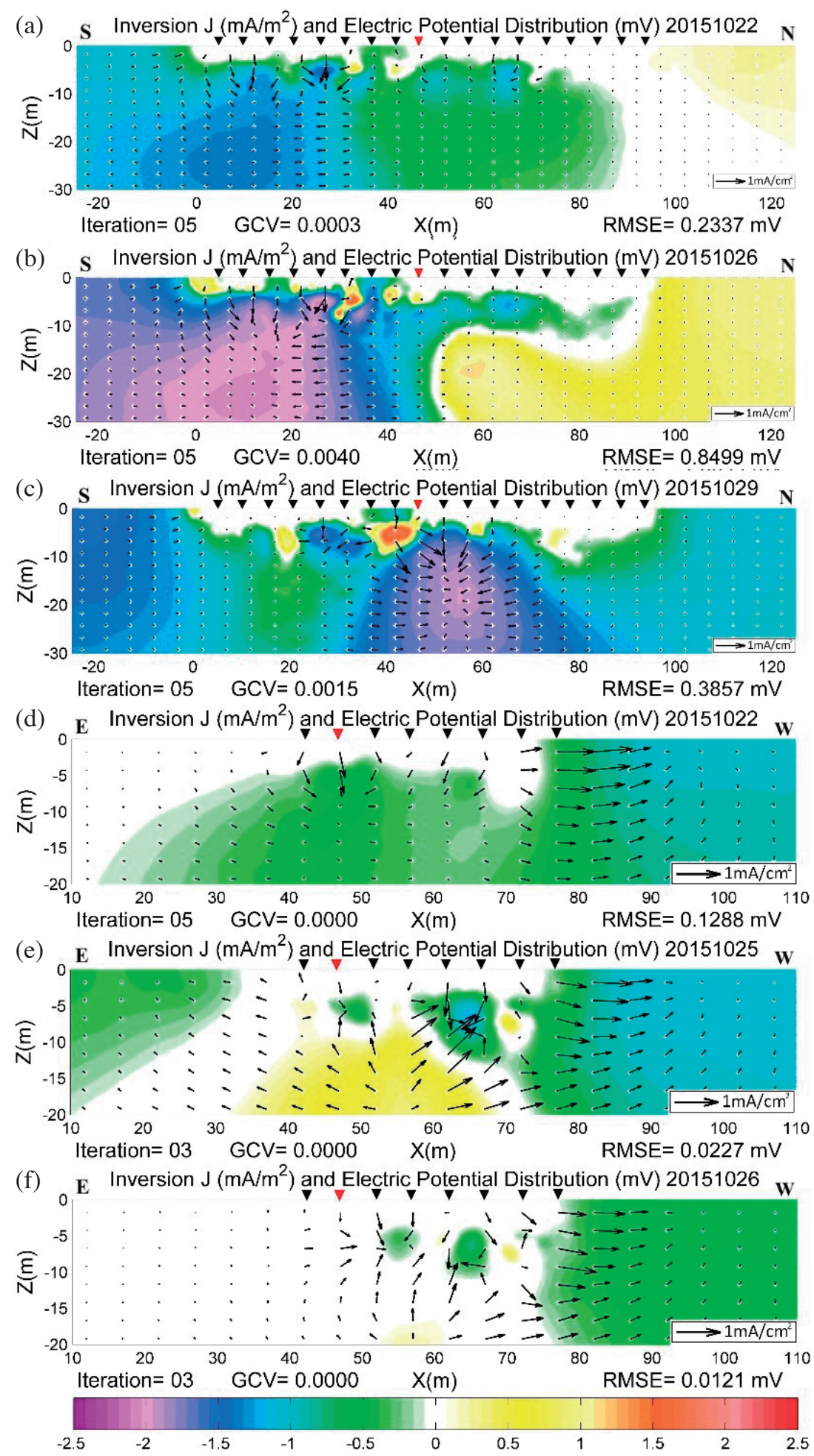

Fig. 6. Self-potential tomographies of rainfall effects in survey lines I and II. The SPTs of survey lines I and II acquired through the inversion of the rainfall response values (daily average SP data of rainfall effects) from Fig. 5 in the SP field. (a) (d) Phase B is the period of a sharp change in the SP field arising from rainfall when the upstream negative electric potential region strengthens; (b) (e) Phase C is the early phase of the SP field recovery when the upstream and downstream negative electric potentials continued strengthening; (c) (f) Phase C' is the later phase of the SP field recovery when the upstream and downstream negative electric potentials gradually weakened. The SPT colorbar is indicated in a logarithmic scale $\left(10 \mathrm{mV}\right.$ will show 1 in colorbar because $\left.\log _{10} 10=1\right)$. 

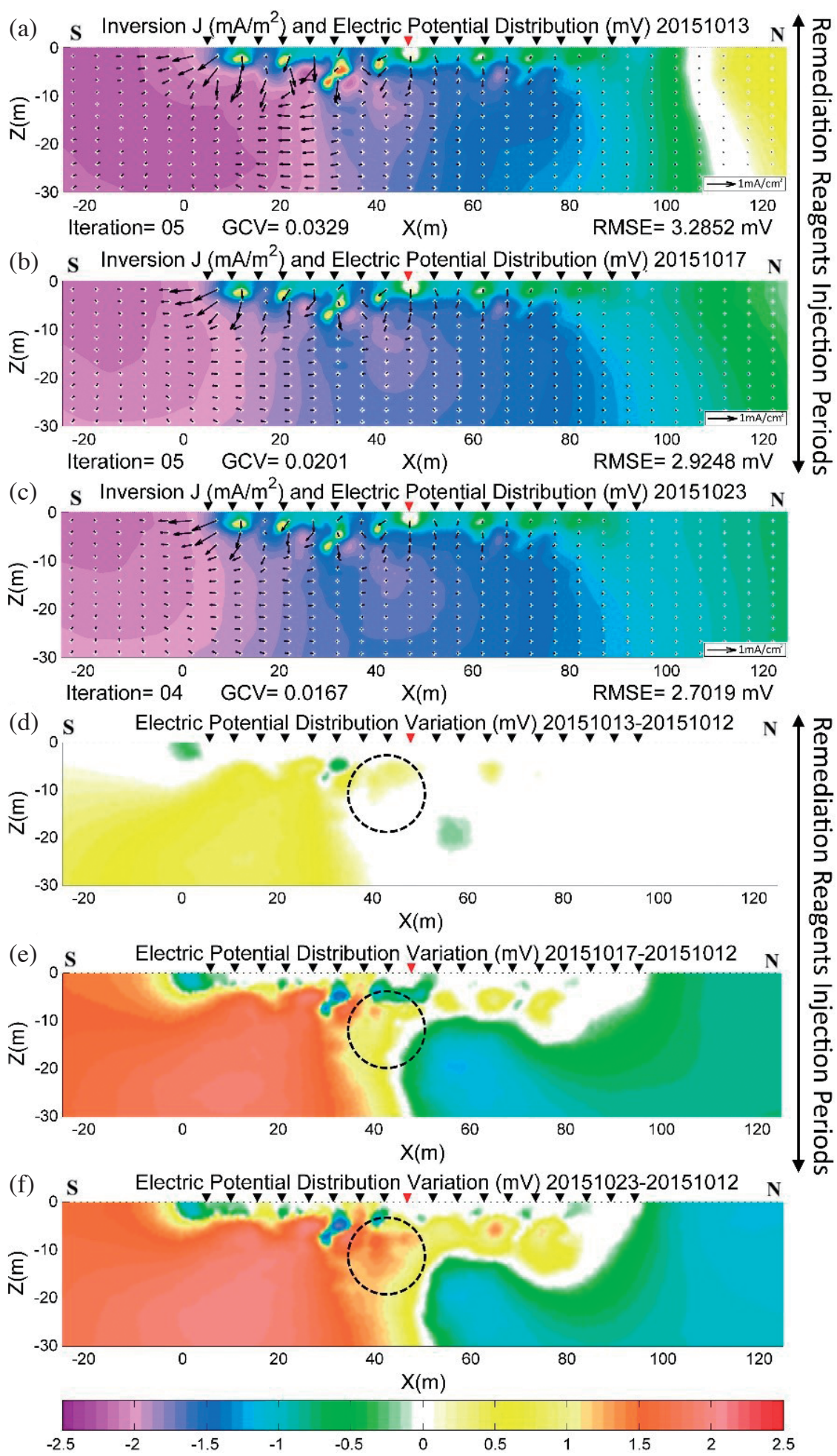

Fig. 7. Daily self-potential tomographies (SPTs) and SPT variations in survey line I on 13,17, and 28 October. A reagent was injected from 13 to 18 October; the rainfall effects on 22 October are shown in Fig. 5 and were corrected. The theoretical values (daily average fitted data) was used for the inversion of SP for continuing the monitoring of the SPTs after reagent injection. (a), (b), and (c) are the SPTs on different dates; (d), (e), and (f) are the SPT variations calculated by setting the SPT on 12 October as the reference. The black circle indicates the point-shaped potential increase arising from reagent injection. The SPT colorbar is indicated in a logarithmic scale $\left(10 \mathrm{mV}\right.$ will show 1 in colorbar because $\left.\log _{10} 10=1\right)$. 
(Figs. 7d, e, and f). The local potential increase in the SPTs of survey line I was nearly coincident with the area of the reagent injection, where is located approximately at $\mathrm{x}=42 \mathrm{~m}$ of line I with the injection depth is from 2 to $17 \mathrm{~m}$. Moreover, with the imaginary boundary being at $\mathrm{x}=40 \mathrm{~m}$, the negative potential region in the south gradually weakened and moved toward the south; the positive potential region in the north also weakened gradually and moved toward the north (Figs. 7a, b, and c).

The daily SPTs and SPT variations in survey line II were similar to those in survey line I on 13, 17, and 23 October. The daily SPT variations in Figs. 8d, e, and f show the potential increased below a depth of $2-15 \mathrm{~m}$ at $\mathrm{x}=$ 52 - $67 \mathrm{~m}$ from 13 to 23 October. The rectangular potential rise, as indicated in Figs. 7d, e, and f, was as high as $10 \mathrm{mV}$. The local potential increase in the SPTs of survey line II was also nearly coincident with the area of the reagent injection, where is located approximately at $\mathrm{x}=52-67 \mathrm{~m}$ of line II with the injection depth is from 2 to $17 \mathrm{~m}$.

Because survey line I was perpendicular to the reagent injection region, and the injection was located in the middle of survey line I, the SPTs were primarily characterized by a point-shaped potential increase, with weakening and movement of the electric potential. By contrast, as survey line II was arranged parallel to the reagent injection region, a rectangular potential increase was observed within the area of the reagent injection in the SPTs. We thus suggest that continuous monitoring of SP can be used as an evaluation tool for the reagent effectiveness.

\section{DISCUSSION}

During dissipation of the rainfall effects in SP in early September, the intensity of potentials to the upstream and downstream gradually weakened (Figs. 9a, b, and c). Therefore, according to the apparent velocity evaluation method adopted in the sandbox saline injection experiment performed by Martínez-Pagán et al. (2010) and the dam leakage survey conducted by Bolève et al. (2011), the time interval for the zero potential boundary to pass two fixed points within a specific distance was adopted to evaluate the apparent velocity of groundwater in this study. Figure 9d shows the variations in the electric potential at a depth of $25 \mathrm{~m}$ at $\mathrm{x}$ $=60 \mathrm{~m}$ (Point A) and $100 \mathrm{~m}$ (Point $\mathrm{B}$ ) in the SPTs of survey line I. The time interval for the passage of the zero electric potential boundary was approximately $12.36 \pm 1.65$ days. The calculation yielded an apparent velocity of groundwater of approximately $3.24 \pm 0.38 \mathrm{~m} \mathrm{day}^{-1}$.

In addition to the use of rainfall dissipation to evaluate the apparent velocity of groundwater, this study detected a continuous potential increase in the injection region during reagent injection on 13 October. The time interval for the isopotential line to pass two fixed points within a specific distance was again adopted to evaluate the apparent hydrau- lic conductivity in the local region in this study. As shown in Fig. 10, the time interval for the potential at a depth of $9 \mathrm{~m}$ at $\mathrm{x}=40 \mathrm{~m}$ (Point A) to increase to that at a depth of $9 \mathrm{~m}$ at $\mathrm{x}=43 \mathrm{~m}$ (Point $\mathrm{B}$ ) on 12 October was approximately 5.92 \pm 0.90 days. The apparent velocity of groundwater was approximately $0.57 \pm 0.08 \mathrm{~m} \mathrm{day}^{-1}$, which is quite well within the range of the flow rate and direction measurements on the contamination site and more closely coincident with the measurements than the value evaluated from the dissipation of rainfall effects (Fig. 11).

Equation (1) shows that variations in the streaming potential and groundwater pressure are correlated. When the groundwater flow pressure increases, the positive and negative charges on both sides of the shear plane are more distinctively separated, thus enhancing the positive and negative potentials of SP. Variations in groundwater pressure and streaming potential can be physically connected through the streaming potential coupling coefficient. Therefore, the apparent hydraulic conductivity evaluated through the movement of the isopotential line does not directly indicate the water permeability of soil. A future research goal must be to determine how to increase the streaming potential through groundwater pressure variations or reagent diffusion and connect these two physical values by using an appropriate streaming potential coupling coefficient.

\section{CONCLUSION}

In this study, the SPTs were continuously monitored to analyze the reagent injection and rainfall effects on the soil and groundwater contamination site. First, the groundwater flow direction in this region was reliably analyzed to be in the north-northeast direction. Second, 1-week-long rainfall yielded a period of a sharp change and the period of recovery, with an intensity of $-100 \mathrm{mV}$. Third, after eliminating the rainfall effects from the SP data, we observed that the reagent injection from 3 to 18 October resulted in the local potential increase. In survey line I, a point-shaped potential increase was observed at a depth of $5-17 \mathrm{~m}$ at $\mathrm{x}=40 \mathrm{~m}$. By contrast, in survey line II, a rectangular potential increase was observed at a depth of $2-15 \mathrm{~m}$ from $\mathrm{x}=52-67 \mathrm{~m}$. Finally, the apparent velocity of groundwater subject to the dissipation of rainfall effect was $3.24 \pm 0.38 \mathrm{~m} \mathrm{day}^{-1}$ and that subject to the reagent injection was $0.57 \pm 0.08 \mathrm{~m} \mathrm{day}^{-1}$. Both evaluations from the dissipation of the rainfall effects and reagent injection were consistently within the range of the flow rate and direction measurements in monitored wells.

The SP method facilitates the real-time monitoring of electric potential fields. Through long-term and stable SPTs, we can not only determine the flow direction of groundwater, but also monitor the variation in electric substances such as reagents. SPTs are highly useful for monitoring soil and groundwater contamination sites in the future. Moreover, the equipment used in the SP method is advantageous because 


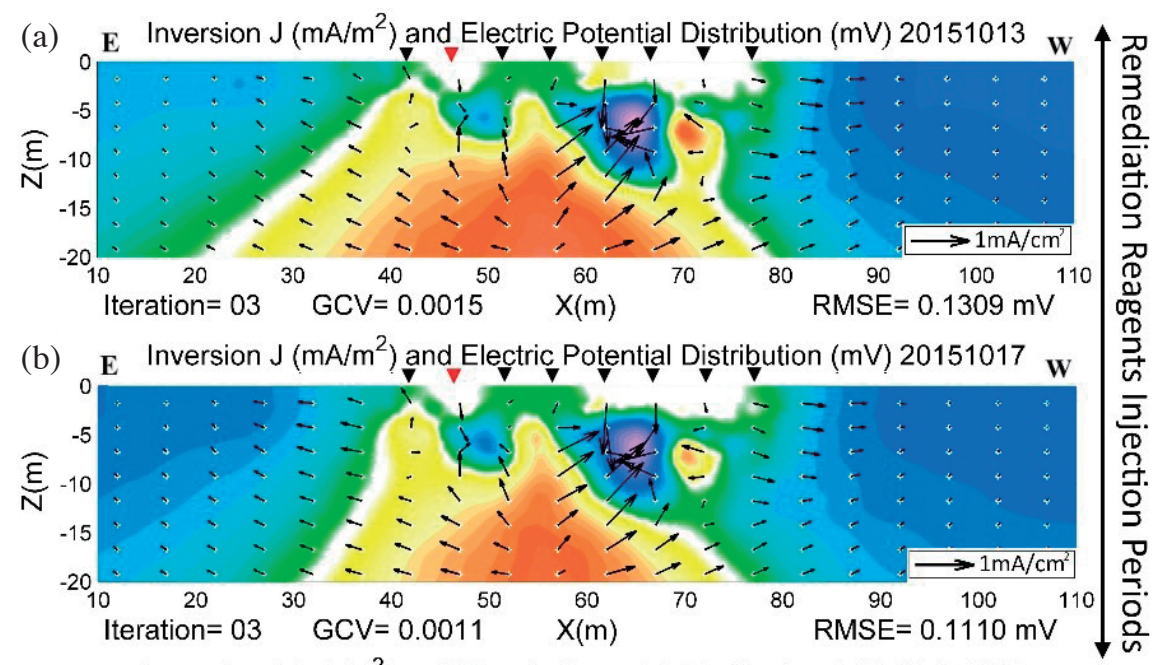

(c) $\mathbf{E}$ Inversion $\mathrm{J}\left(\mathrm{mA} / \mathrm{m}^{2}\right)$ and Electric Potential Distribution (mV) $20151023 \mathbf{W}$

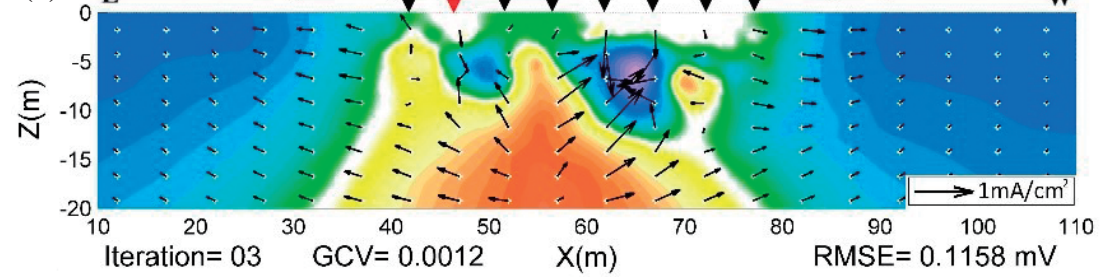

(d) $\mathbf{E} \quad$ Electric Potential Distribution Variation $(\mathrm{mV}) 20151013-20151012 \quad$ w

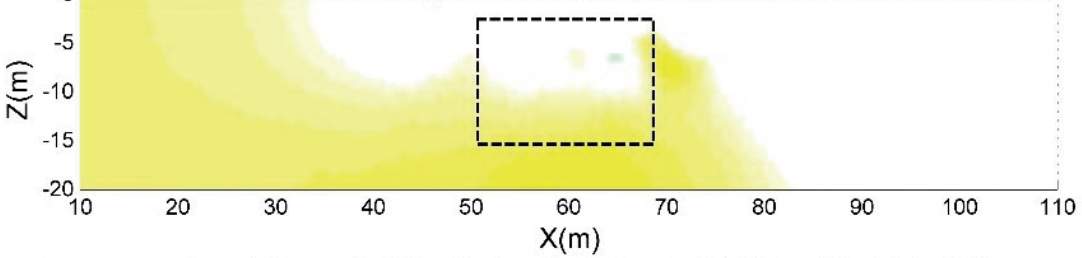

(e) $\mathbf{E} \quad$ Electric Potential Distribution Variation $(m \vee) 20151017-20151012$ w

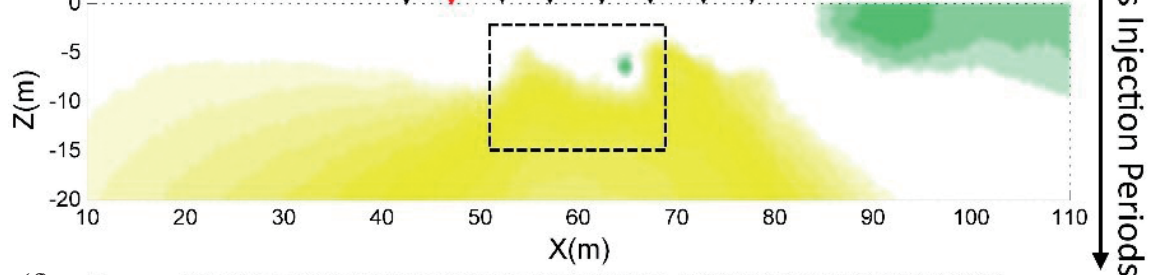

(f) $\mathbf{E} \quad$ Electric Potential Distribution Variation $\left(\mathrm{m}_{\nabla} \mathrm{V}\right) \underset{\nabla}{\mathbf{\nabla}} 20151023-20151012$ W
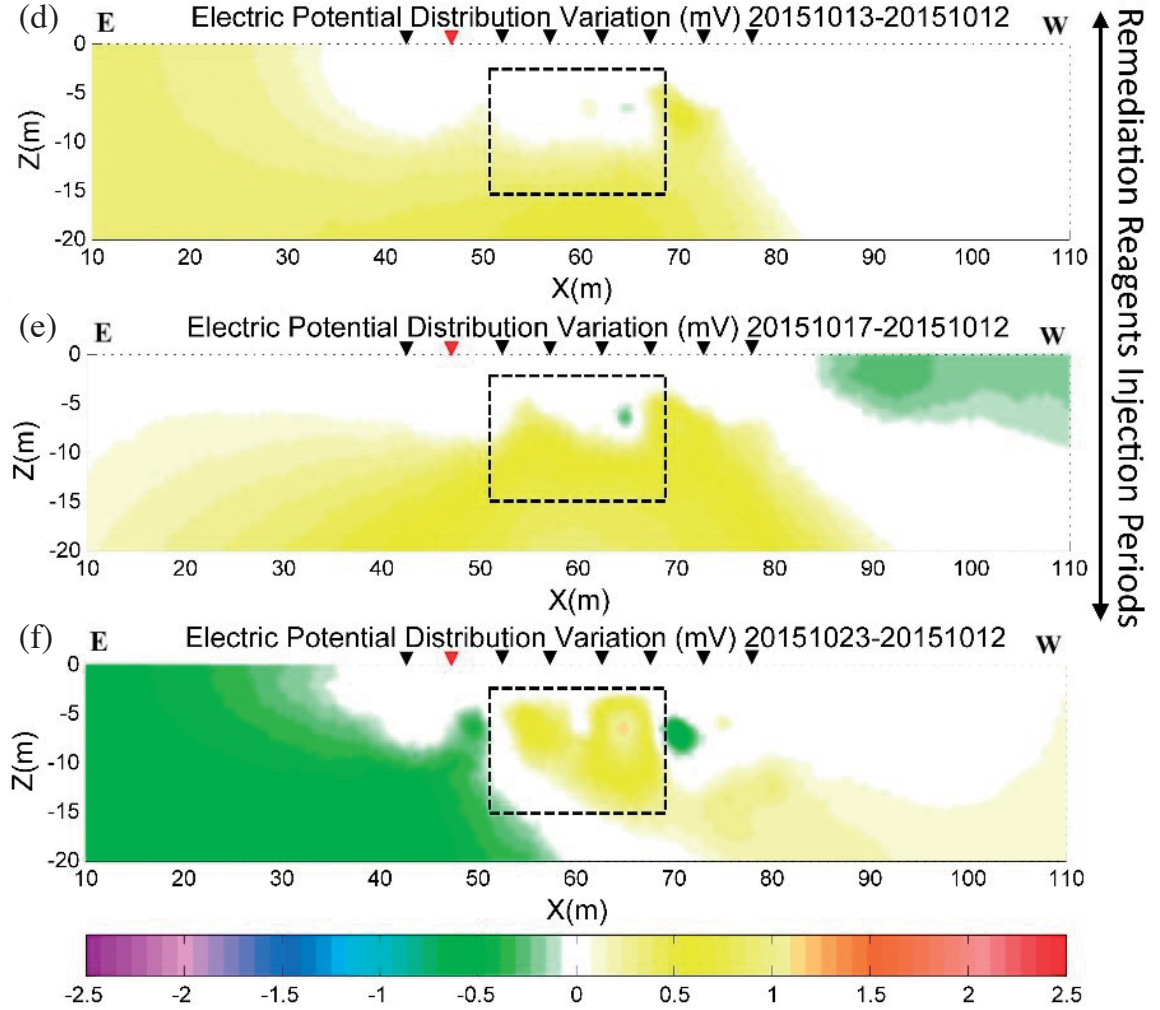

Fig. 8. Daily self-potential tomographies (SPTs) and SPT variations in survey line II on 13, 17, and 28. A reagent was injected from 13 to 18 October; the rainfall effects on 22 October are shown in Fig. 5 and were corrected. The theoretical values (daily average fitted data) was used for the inversion of SP for continuing the monitoring of SPTs after the reagent injection. (a), (b), and (c) are the SPTs on different dates; (d), (e), and (f) are the SPT variations calculated by setting the SPT on 12 October as the base reference. The black block indicates the rectangular potential increase arising from reagent injection. The SPT colorbar is indicated in a logarithmic scale $\left(10 \mathrm{mV}\right.$ will show 1 in colorbar because $\left.\log _{10} 10=1\right)$. 

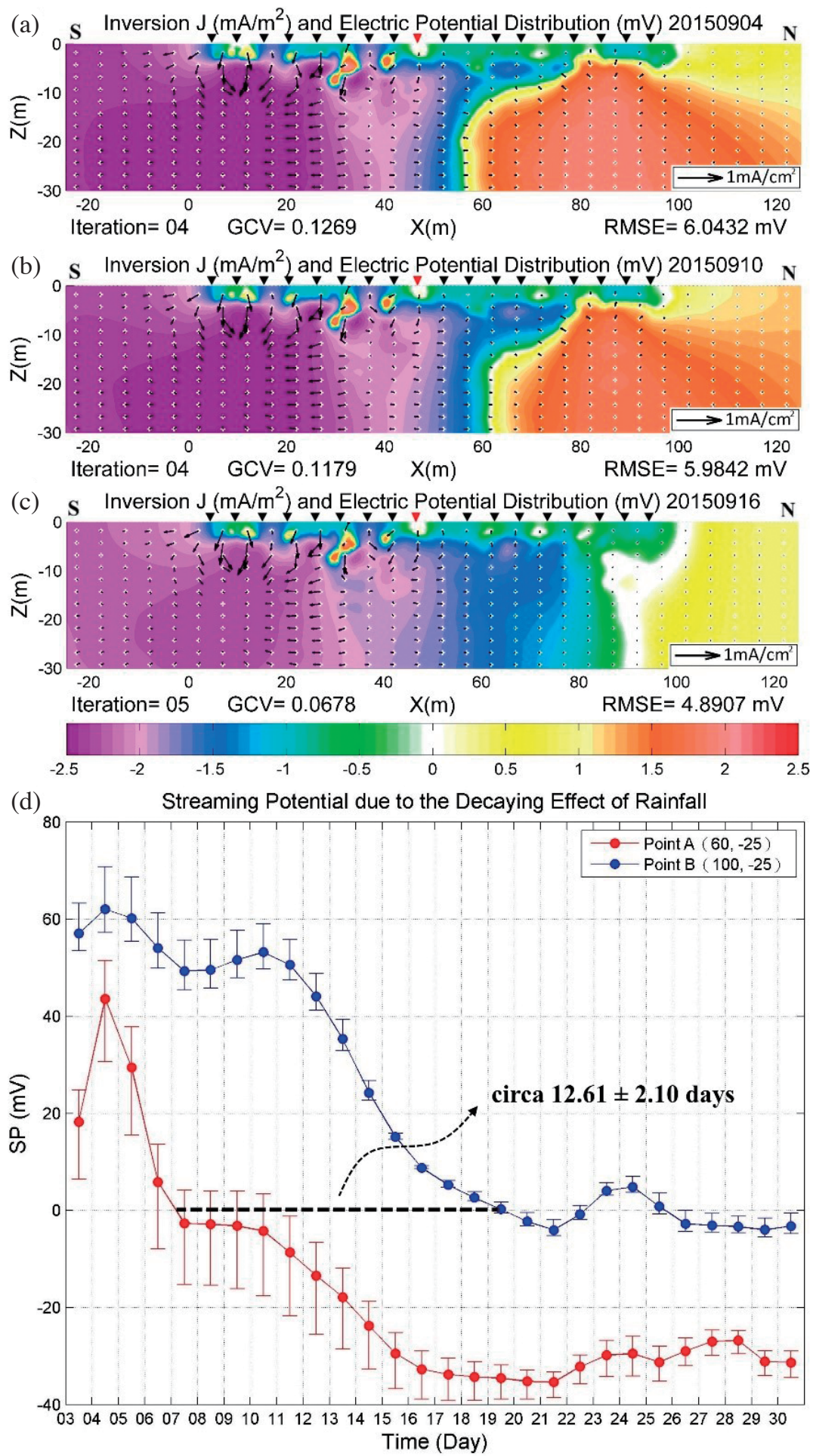

Fig. 9. Variation in the electric potential at a depth of $25 \mathrm{~m}$ at $\mathrm{x}=60 \mathrm{~m}$ (Point A) and $100 \mathrm{~m}$ (Point B) in the self-potential tomographies (SPTs) of survey line I from 3 to 30 September. The upper and lower limits of error at Points A and B are the potential differences at a horizontal distance of $2.5 \mathrm{~m}$. As shown in (a), (b), and (c), the upstream negative potential and downstream positive potential continued weakening during the continuous sunny days in early September. According to the time interval for the zero potential boundary to pass through the depth of $25 \mathrm{~m}$ at $\mathrm{x}=60 \mathrm{~m}$ (Point A) and $100 \mathrm{~m}$ (Point B), the apparent velocity of groundwater was $3.24 \pm 0.38 \mathrm{~m} \mathrm{day}^{-1}$. 


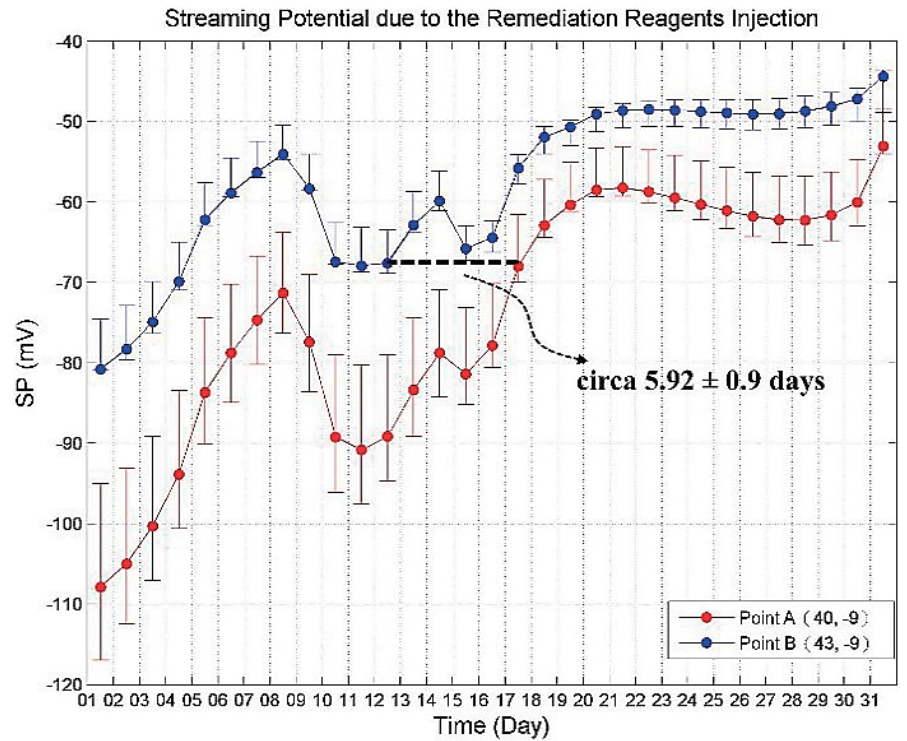

Fig. 10. Variations in the Electric potential at a Depth of $8 \mathrm{~m}$ at $\mathrm{x}=40 \mathrm{~m}$ (Point A) and $43 \mathrm{~m}$ (Point B) in the self-potential tomographies (SPTs) of survey line I from 3 to 31 October. The upper and lower limits of error at Points A and B are the potential differences at a horizontal distance of $1 \mathrm{~m}$. Figure 7 shows that the electric potential increased continuously in the injection region when the reagent injection started on 13 October. According to the measured time interval for the potential of Point A to increase to the potential of Point B on 12 October, the apparent velocity of groundwater was $0.57 \pm 0.08 \mathrm{~m}^{\text {day }}{ }^{-1}$.

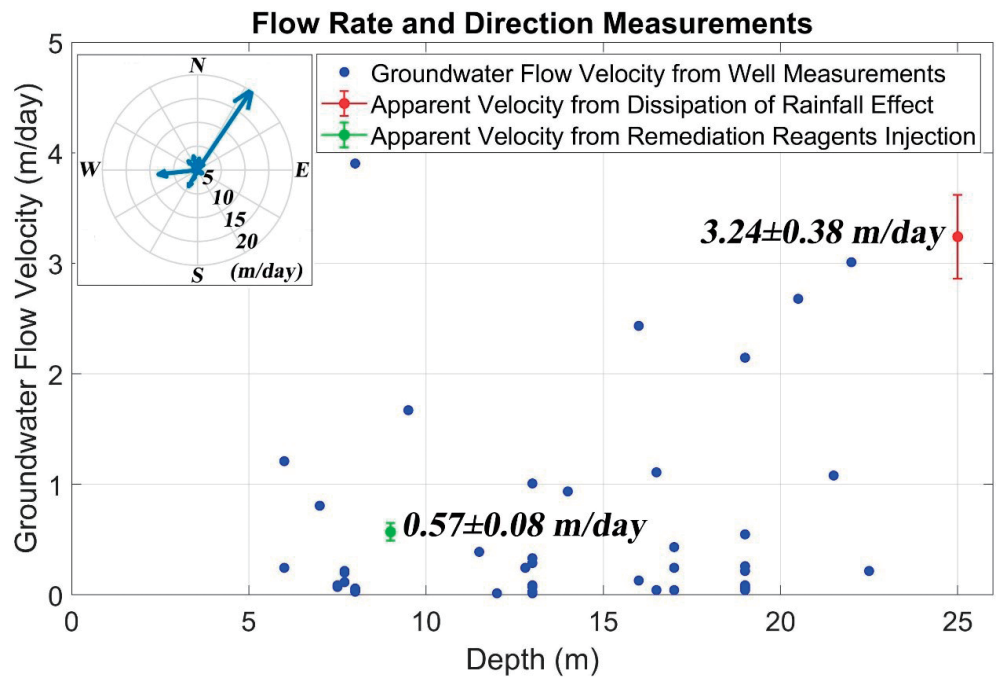

Fig. 11. Flow rate and direction measurements. The groundwater flow rates and directions were measured from wells indicated in Fig. 1. Heterogeneous strata have highly different hydraulic conductivity because the contamination site is composed of paleochannel alluvium. The rose figure shows that the direction at the maximum flow rate is in the NNE direction. The apparent velocity of groundwater subject to the dissipation of rainfall effects and reagent diffusion were within the range of the flow rate measurements at different depths. 
of easy and economical deployment as well as continuous data. Establishing a system connecting SP and the groundwater transmission process deserves long-term commitment.

Acknowledgements We would like to thank Soil and Groundwater Pollution Remediation Fund Management Board for the support of this study. This study was funded under grant EPA-103-GA12-03-A296 and EPA-105-GA1303-A271 of the Environmental Protection Administration, Executive Yuan, R.O.C. CCC is also grateful for research support from the Ministry of Science and Technology, R.O.C., and the Graduate Institute of Geophysics, National Central University, R.O.C.

\section{REFERENCES}

Al-Saigh, N.H., Z. S. Mohammed, and M. S. Dahham, 1994: Detection of water leakage from dams by self-potential method. Eng. Geol., 37, 115-121, doi: 10.1016/00137952(94)90046-9. [Link]

Annan, A. P., 2005: GPR methods for hydrogeological studies. In: Rubin, Y. and S. S. Hubbard (Eds.), Hydrogeophysics, Water Science and Technology Library, Vol. 50, Springer, Dordrecht, 185-213, doi: 10.1007/14020-3102-5_7. [Link]

Arora, T., N. Linde, A. Revil, and J. Castermant, 2007: Non-intrusive characterization of the redox potential of landfill leachate plumes from self-potential data. $J$. Contam. Hydrol., 92, 274-292, doi: 10.1016/j.jconhyd.2007.01.018. [Link]

Atekwana, E. A. and E. A. Atekwana, 2010: Geophysical signatures of microbial activity at hydrocarbon contaminated sites: A review. Surv. Geophys., 31, 247283, doi: 10.1007/s10712-009-9089-8. [Link]

Baker, S. S. and J. P. Cull, 2004: Streaming potential and groundwater contamination. Explor. Geophys., 35, 4144, doi: 10.1071/eg04041. [Link]

Benson, A. K., K. L. Payne, and M. A. Stubben, 1997: Mapping groundwater contamination using dc resistivity and VLF geophysical methods-A case study. Geophysics, 62, 80-86, doi: 10.1190/1.1444148. [Link]

Binley, A. and A. Kemna, 2005: DC resistivity and induced polarization methods. In: Rubin, Y. and S. S. Hubbard (Eds.), Hydrogeophysics, Water Science and Technology Library, Vol. 50, Springer, Dordrecht, 129-156, doi: 10.1007/1-4020-3102-5_5. [Link]

Birch, F. S., 1993: Testing Fournier's method for finding water table from self-potential. Ground Water, 31, 5056, doi: 10.1111/j.1745-6584.1993.tb00827.x. [Link]

Bolève, A., A. Revil, F. Janod, J. L. Mattiuzzo, and J.-J. Fry, 2009: Preferential fluid flow pathways in embankment dams imaged by self-potential tomography. Near Surface Geophysics, 7, 447-462, doi: 10.3997/18730604.2009012. [Link]
Bolève, A., F. Janod, A. Revil, A. Lafon, and J.-J. Fry, 2011: Localization and quantification of leakages in dams using time-lapse self-potential measurements associated with salt tracer injection. J. Hydrol., 403, 242-252, doi: 10.1016/j.jhydrol.2011.04.008. [Link]

Colangelo, G., V. Lapenna, A. Perrone, S. Piscitelli, and L. Telesca, 2006: 2D Self-Potential tomographies for studying groundwater flows in the Varco d'Izzo landslide (Basilicata, southern Italy). Eng. Geol., 88, 274286, doi: 10.1016/j.enggeo.2006.09.014. [Link]

Corwin, R. F. and D. B. Hoover, 1979: The self-potential method in geothermal exploration. Geophysics, 44, 226-245, doi: 10.1190/1.1440964. [Link]

Everett, M. E. and M. A. Meju, 2005: Near-surface controlled-source electromagnetic induction. In: Rubin, Y. and S. S. Hubbard (Eds.), Hydrogeophysics, Water Science and Technology Library, Vol. 50, Springer, Dordrecht, 157-183, doi: 10.1007/1-4020-3102-5_6. [Link]

Fagerlund, F. and G. Heinson, 2003: Detecting subsurface groundwater flow in fractured rock using self-potential (SP) methods. Environ. Geol., 43, 782-794, doi: 10.1007/s00254-002-0693-x. [Link]

Fournier, C., 1989: Spontaneous potentials and resistivity surveys applied to hydrogeology in a volcanic area: Case history of the chaîne des Puys (Puy-deDôme, France). Geophys. Prospect., 37, 647-668, doi: 10.1111/j.1365-2478.1989.tb02228.x. [Link]

Glover, P. W. and M. D. Jackson, 2010: Borehole electrokinetics. The Leading Edge, 29, 724-728, doi: 10.1190/1.3447786. [Link]

Hansen, P. C., 1998: Rank-Deficient and Discrete Ill-Posed Problems: Numerical Aspects of Linear Inversion, Society for Industrial and Applied Mathematics, 263 pp, doi: 10.1137/1.9780898719697. [Link]

Hashimoto, T. and Y. Tanaka, 1995: A large self-potential anomaly on Unzen volcano, Shimabara peninsula, Kyushu island, Japan. Geophys. Res. Lett., 22, 191-194, doi: 10.1029/94g103077. [Link]

Jardani, A., J. P. Dupont, and A. Revil, 2006: Self-potential signals associated with preferential groundwater flow pathways in sinkholes. J. Geophys. Res., 111, doi: 10.1029/2005jb004231. [Link]

Jardani, A., A. Revil, W. Barrash, A. Crespy, E. Rizzo, S. Straface, M.Cardiff, B. Malama, C. Miller, and T. Johnson, 2009: Reconstruction of the water table from selfpotential data: A Bayesian approach. Ground Water, 47, 213-227, doi: 10.1111/j.1745-6584.2008.00513.x. [Link]

Jouniaux, L., M. L. Bernard, M. Zamora, and J. P. Pozzi, 2000: Streaming potential in volcanic rocks from Mount Pelée. J. Geophys. Res., 105, 8391-8401, doi: 10.1029/1999jb900435. [Link]

Lapenna, V., P. Lorenzo, A. Perrone, S. Piscitelli, F. Sdao, 
and E. Rizzo, 2003: High-resolution geoelectrical tomographies in the study of Giarrossa landslide (southern Italy). Bull. Eng. Geol. Environ., 62, 259-268, doi: 10.1007/s10064-002-0184-z. [Link]

Martínez-Pagán, P., A. Jardani, A. Revil, and A. Haas, 2010: Self-potential monitoring of a salt plume. Geophysics, 75, WA17-WA25, doi: 10.1190/1.3475533. [Link]

Mauritsch, H. J., W. Seiberl, R. Arndt, A. Römer, K. Schneiderbauer, and G. P. Sendlhofer, 2000: Geophysical investigations of large landslides in the Carnic region of southern Austria. Eng. Geol., 56, 373-388, doi: 10.1016/s0013-7952(99)00120-9. [Link]

Milsom, J., 2007: Field Geophysics, 3rd Edition, John Wiley and Sons, $244 \mathrm{pp}$.

Naudet, V., A. Revil, J.-Y. Bottero, and P. Bégassat, 2003: Relationship between self-potential (SP) signals and redox conditions in contaminated groundwater. Geophys.Res.Lett., 30, doi: 10.1029/2003g1018096. [Link]

Naudet, V., A. Revil, E. Rizzo, J.-Y. Bottero, and P. Bégassat, 2004: Groundwater redox conditions and conductivity in a contaminant plume from geoelectrical investigations. Hydrol. Earth Syst. Sci., 8, 8-22, doi: 10.5194/hess-8-8-2004. [Link]

Patella, D., 1997: Self-potential global tomography including topographic effects. Geophys. Prospect., 45, 843863, doi: 10.1046/j.1365-2478.1997.570296.x. [Link]

Perrier, F., M. Trique, J. Aupiais, U. Gautam, and P. Shrestha, 1999: Electric potential variations associated with periodic spring discharge in western Nepal. Comptes Rendus de l'Académie des Sciences - Series IIA - Earth and Planetary Science, 328, 73-79, doi: 10.1016/ s1251-8050(99)80001-9. [Link]

Revil, A., D. Hermitte, M. Voltz, R. Moussa, J.-G. Lacas, G. Bourrié, and F. Trolard, 2002: Self-potential signals associated with variations of the hydraulic head during an infiltration experiment. Geophys. Res. Lett., 29, 101-10-4, doi: 10.1029/2001g1014294. [Link]

Revil, A., K. Titov, C. Doussan, and V. Lapenna, 2006: Applications of the self-potential method to hydrological problems. In: Vereecken, H., A. Binley, G. Cassiani, A. Revil, and K. Titov (Eds.), Applied Hydrogeophysics, NATO Science Series, Vol. 71, Springer, Dordrecht, 255-292, doi: 10.1007/978-1-4020-4912-5_9. [Link]

Sauck, W. A., E. A. Atekwana, and M. S. Nash, 1998: High conductivities associated with an LNAPL plume imaged by integrated geophysical techniques. Journal of Environmental and Engineering Geophysics, 2, 203-212.

Sheffer, M. R. and J. A. Howie, 2001: Imaging subsurface seepage conditions through the modeling of streaming potential. Proceedings of the 54th Canadian Geotechnical Conference, Richmond, BC, Canada, 1094-1101.

Sheffer, M. R. and J. A. Howie, 2003: A numerical modelling procedure for the study of the streaming potential phenomenon in embankment dams. 16th EEGS Symposium on the Application of Geophysics to Engineering and Environmental Problems, cp-190-00046, European Association of Geoscientists \& Engineers, San Antonio, Texas, USA, 475-487, doi: 10.3997/22144609-pdb.190.ele05. [Link]

Slater, L. D. and D. Lesmes, 2002: IP interpretation in environmental investigations. Geophysics, 67, 77-88, doi: 10.1190/1.1451353. [Link]

Sogade, J. A., F. Scira-Scappuzzo, Y. Vichabian, W. Shi, W. Rodi, D. P. Lesmes, and F. D. Morgan, 2006: Induced-polarization detection and mapping of contaminant plumes. Geophysics, 71, B75-B84, doi: 10.1190/1.2196873. [Link]

Soueid Ahmed, A., A. Jardani, A. Revil, and J. P. Dupont, 2013: SP2DINV: A 2D forward and inverse code for streaming potential problems. Comput. Geosci., 59, 9-16, doi: 10.1016/j.cageo.2013.05.008. [Link]

Tanaka, Y., 1993: Eruption mechanism as inferred from geomagnetic changes with special attention to the 1989-1990 activity of Aso Volcano. J. Volcanol. Geotherm. Res., 56, 319-338, doi: 10.1016/03770273(93)90024-1. [Link]

Trique, M., P. Richon, F. Perrier, J. P. Avouac, and J. C. Sabroux, 1999: Radon emanation and electric potential variations associated with transient deformation near reservoir lakes. Nature, 399, 137-141, doi: 10.1038/20161. [Link]

Wang, T.-P., C.-C. Chen, L.-T. Tong, P.-Y. Chang, Y.-C. Chen, T.-H. Dong, H.-C. Liu, C.-P. Lin, K.-H. Yang, C.-J. Ho, and S.-N. Cheng, 2015: Applying FDEM, ERT and GPR at a site with soil contamination: A case study. J. Appl. Geophys., 121, 21-30, doi: 10.1016/j. jappgeo.2015.07.005. [Link] 